\title{
Study on Anti-collapse Behavior of Solar Greenhouses Covering Rigid Plate under Snowstorm
}

\author{
Chuanjia Hu, Yujia Dai, Jiahe Wang, Mengyan Song, Xiugen Jiang, and Min Ding* \\ Department of Civil Engineering, China Agricultural University, Beijing 100083, China \\ \{chuanjiahu, xrksmy\}@163.com, 530979347@qq.com, wjh_414@sohu.com, \\ jiangxiugeng@tsinghua.org.cn, dingmin2008@gmail.com
}

\begin{abstract}
To analyze the effect of stressed skin action of rigid plate covering on anti-collapse behavior of solar greenhouses under snow load, the numerical simulation on the overall collapse process of single skeleton structure and 6skeleton overall spatial structure with rigid plate covering were conducted on ANSYS. The collapse modes of solar greenhouses and snow load-displacement curves were obtained. The effects of different parameters on the anti-collapse behavior of solar greenhouses under snow load were also analyzed. The results showed that the stressed skin action of the covering could provide lateral support for the skeleton and increase integral rigidity of the structure and the bearing capacity to resist snowstorm. The lateral support of $8 \mathrm{~mm}$ thick PC sun board equals that of 4 purlins, 10mm thick PC sun board equals 6 purlins, and $12 \mathrm{~mm}$ thick PC sun board equals 8 purlins. It is suggested that skeleton interval is about $1 \mathrm{~m}$.
\end{abstract}

Keywords: solar greenhouses, rigid plate covering, stressed skin action, anticollapse behavior, snow load.

\section{Introduction}

The solar greenhouse is an agricultural building as well as a production facility. Its security under various loads is always the priority [1-4]. Much research on solar greenhouses has been focused on the lighting, insulation, heat transfer etc., whereas little was on mechanical behavior and design methods [5-7]. The lack of scientific guidance to the construction of solar greenhouses leads to many accidents, especially during extreme snowstorms in recent years [8,9]. The collapse not only causes the loss of greenhouse facilities but also results in a pause in agricultural production. Therefore, it is essential to investigate the mechanical behavior and the collapse mechanism of solar greenhouses under various loads.

Stressed skin action refers to the strengthening effect of building's surface covering on structure's integral rigidity with its own rigidity and strength [10]. It is always treated as only a structural safety reserve in the construction. This can sometimes achieve simply safety results. But sometimes the result is opposite. The translucent covering can be used as lateral support for the greenhouse skeleton when it is rigid plate such as PC sun board or plate glass etc. Then the contribution to 
integral rigidity from rigid plate covering can be used. This can ensure structure security with less or no extra lateral support systems. The economy objective can thus be achieved. However, research on stressed skin action has only been emphasized in light steel frames and rigid-framed structures at present. There was little research on collapse mechanism and design theory about solar greenhouse considering stressed skin action of rigid plate. In order to make designing model of solar greenhouse better match with the actual working state, and to ensure its security and economy under extreme snowstorms, it becomes necessary to develop this research.

The numerical simulation on overall collapse process of solar greenhouses with rigid plate covering under snow load is carried out on ANSYS. The effects of parameters including component material, structure size and construction techniques on anti-collapse behavior of solar greenhouses under snowstorm are discussed.

\section{$2 \quad$ Finite Element Model}

\subsection{Solar Greenhouse Dimension}

The sectional view and dimensions of selected solar greenhouse (Liaoshen I type) are shown in Fig. 1 and table 1. Single circular steel tube is used as the skeleton [5]. The back wall is reinforced concrete structure [11].

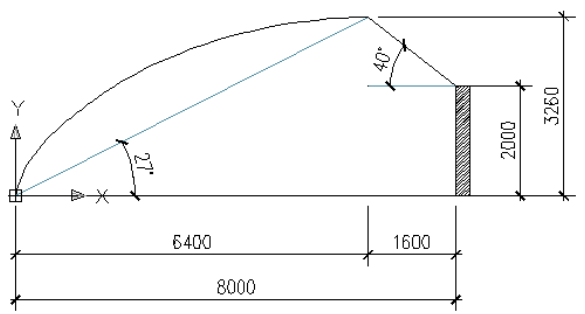

Fig. 1. Sectional view of the solar greenhouse

Table 1. The solar greenhouse dimension [8]

\begin{tabular}{cc|cc}
\hline Parameter & Value & Parameter & Value \\
\hline Span & $8.00 \mathrm{~m}$ & Projected length of front slope & $6.40 \mathrm{~m}$ \\
Ridge height & $3.26 \mathrm{~m}$ & Projected length of back slope & $1.60 \mathrm{~m}$ \\
Elevation of front roof & $27^{\circ}$ & Height of back wall & $2.00 \mathrm{~m}$ \\
Elevation of back roof & $40^{\circ}$ & Reference interval of skeleton & $1.00 \mathrm{~m}$ \\
\hline
\end{tabular}

In practice of Liaoshen I type, skeleton interval is generally $1 \mathrm{~m}$ and the section size of circular steel tube is generally $30 \mathrm{~mm} \times 2 \mathrm{~mm}$, both of which are regarded as reference dimension. Rigid plate covering of solar greenhouse generally consists of PC sun board or plate glass etc. [11]. The thickness is generally from $6 \mathrm{~mm}$ to $12 \mathrm{~mm}$. 
$8 \mathrm{~mm}$ thick PC sun board is used as the reference. The 6-skeleton overall spatial structure with rigid plate covering and no purlins is used as the reference model (hereinafter referred to overall spatial structure) to investigate the effect of rigid plate on anti-collapse behavior of solar greenhouse structure.

\subsection{Material Model}

Structural steel of solar greenhouses is Q235 steel and the multi-linear kinematic hardening elastic-plastic model is used as its stress-strain relation to take material plasticity changes [12]. Mechanical properties of the steel, the PC sun board, and the plate glass are shown in Table 2. VonMises yield criterion is used as the criterion of all materials.

Table 2. Mechanical properties of materials [5, 12, 14, 15]

\begin{tabular}{lccccc}
\hline Materials & $\begin{array}{c}\text { Thick- } \\
\text { ness } \\
(\mathrm{mm})\end{array}$ & $\begin{array}{c}\text { Density } \\
\rho \\
\left(\mathrm{kg} \cdot \mathrm{m}^{3}\right)\end{array}$ & $\begin{array}{c}\text { Poisson } \\
\text { ratio }\end{array}$ & $\begin{array}{c}\text { Elastic } \\
\text { modulus }\end{array}$ & $\begin{array}{c}\text { Yield } \\
\text { stress } \\
(\mathrm{MPa})\end{array}$ \\
\hline Q235 & 2 & 7850 & 0.3 & 206 & 235 \\
Plate glass & 5 & 2400 & 0.25 & 70 & 58.8 \\
PC sun board & 8 & 1200 & 0.3 & 2.4 & 63 \\
\hline
\end{tabular}

\subsection{Element Type and Meshing}

The ANSYS element BEAM188 is chosen for solar greenhouse skeleton. To PC sun board (hereinafter referred to as stressed skin), element SHELL181 is suitable for its consideration of in-plane shear deformation. Every single skeleton is divided into 40 units, and the stressed skin is divided into hexahedral elements using rules of free meshing [13].

\subsection{Constraint Condition and Loading Mode}

Only translational degrees of freedom of stressed skin elements are coupled with those of beam elements. Constraint condition takes the case both top and bottom hinged as the reference condition. The loading mode is to impose on the skeleton vertical down line load $q$ to simulate snow load. The snow load can be conversed from the line load by multiplying $q$ with skeleton length, and then dividing stressed skin area between two adjacent single skeletons. In this paper, the ultimate load refers to ultimate snow load.

\subsection{Calculation Model and Analysis Method}

Finite element models of solar greenhouse structure are created according to the method above, and shown in Fig. 2. 


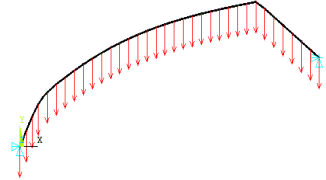

(a) Single skeleton structure

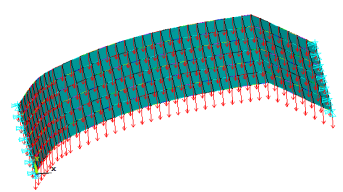

(b) Overall spatial structure

Fig. 2. Calculation models of solar greenhouse

The displacement of solar greenhouse structure under actual loads is always very large due to the softness of components. Large displacement affects bearing capacity $[12,16]$. Therefore, the NL GEOM command is opened to activate the large deformation effect in the analyzing process. Arc-length method based on Newton's law of Laplace is adopted. It is convenient to use static analysis of progressive loading to obtain the structure's ultimate bearing capacity by means of reasonable adjustments to overall load and loading sub-steps [17]. The descent stage of snow loaddisplacement curves can be received via arc-length method. And the vertex of the curve is the theoretical ultimate bearing capacity of the structure [18].

\section{Results Comparison}

\subsection{Effect of Different Structural Calculation Model}

Solar greenhouse structure is usually simplified to two-hinged arch structure or twohinge truss arch structure to calculate the strength and deformation in plane ignoring the interaction and contribution of covering material to the greenhouse structural capacity.

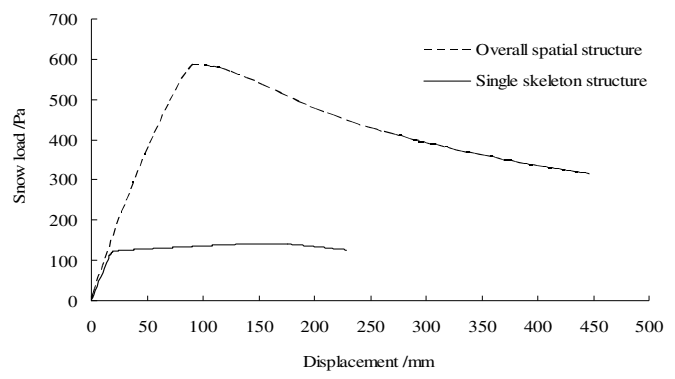

Fig. 3. Snow load-displacement curves of different structural calculation model

As shown in Fig.3, in the elastic stage, vertical deformation of the structure increases with the snow load increasing. After the ultimate load, the curve of overall spatial structure begins to decline, while the curve of single skeleton structure becomes horizontal. The ultimate load of overall spatial structure is $582 \mathrm{~Pa}$ and the maximum displacement is $448 \mathrm{~mm}$. The ultimate load of single skeleton structure is only $142 \mathrm{~Pa}$ and the maximum displacement is $227 \mathrm{~mm}$. The ultimate load of the former is 4.10 times of that of the latter, and the maximum displacement of the former 
is 1.97 times of that of the latter. The reason is that the single skeleton structure has no lateral restraint support systems. Its collapse mode is out-of-plane buckling, and the steel does not fully play its role. Whereas with the lateral support provided by the stressed skin, the collapse mode of overall spatial structure is in-plane buckling, and the steel can fully play its role.

Fig.4 and Fig.5 present the comparison results of deformation before and after the ultimate load to show the buckling modes of different structural calculation models.

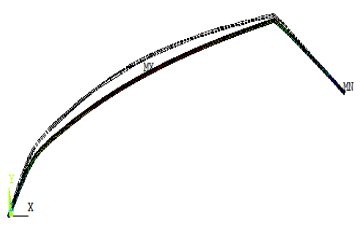

(a) Front view

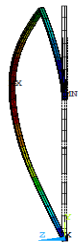

(b) Right view

Fig. 4. Deformation of single skeleton structure

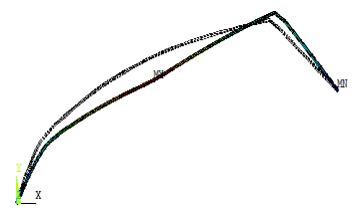

(a) Front view

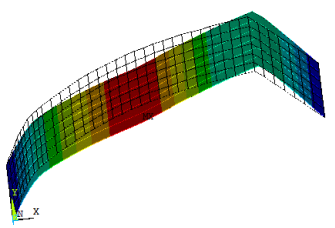

(b) Isometric view

Fig. 5. Deformation of overall spatial structure

\subsection{Effect of Different Number of Purlins}

According to Part 2.1, rigid plate covering can effectively improve the bearing capacity to resist snowstorms and it can partly replace purlins to prevent out-of-plane buckling of skeletons. Here, the cross section of purlins is circular steel, and its section size is $10 \mathrm{~mm} \times 1 \mathrm{~mm}$.

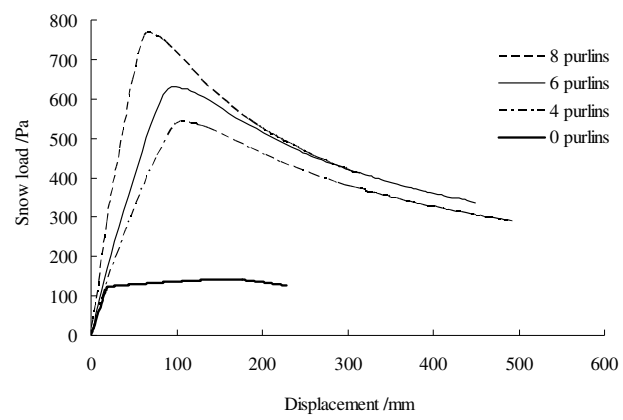

Fig. 6. Snow load-displacement curves of structures with different purlins 
As shown in Fig.6, without covering materials, the more the purlins are, the greater ultimate load is, and the smaller the maximum displacement is. Curves of structures with 4, 6 and 8 purlins are similar in shape. It indicates that they have the same collapse modes and all of them are in-plane buckling. The ultimate load of the structures with 4, 6 and 8 purlins is respectively $537 \mathrm{~Pa}, 627 \mathrm{~Pa}$ and $761 \mathrm{~Pa}$, increased by $16.8 \%$ and $21.4 \%$ in order. The structure without purlins and covering materials is equivalent to single skeleton structure. To compare with previous models, the deformation diagrams of overall spatial structure with 6 purlins are presented, as shown in Fig.7.

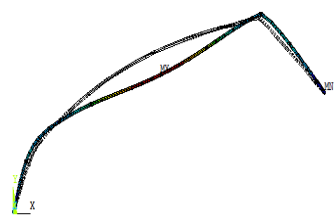

(a) Front view

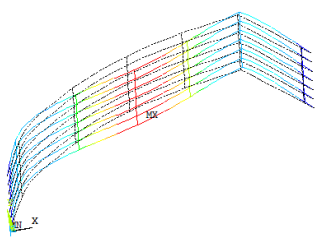

(b) Isometric view

Fig. 7. Deformation diagrams of the structure with 6 purlins

\subsection{Effect of Different Skeleton Interval}

As shown in Fig.8, changing skeleton interval is equivalent to change the degree of lateral support of stress skin on the structure. The greater the skeleton interval is, the smaller the ultimate load is, and the greater the maximum displacement is. The shape of curves of structures with different skeleton interval is similar, and collapse modes are all in-plane buckling. The ultimate load of structures with $1 \mathrm{~m}, 1.5 \mathrm{~m}$ and $2 \mathrm{~m}$ skeleton interval is respectively $582 \mathrm{~Pa}, 492 \mathrm{~Pa}$ and $358 \mathrm{~Pa}$, reduced by $15.5 \%$ and $27.2 \%$ in order. The recommended skeleton interval is $1 \mathrm{~m}$ considering the supporting role of stressed skin.

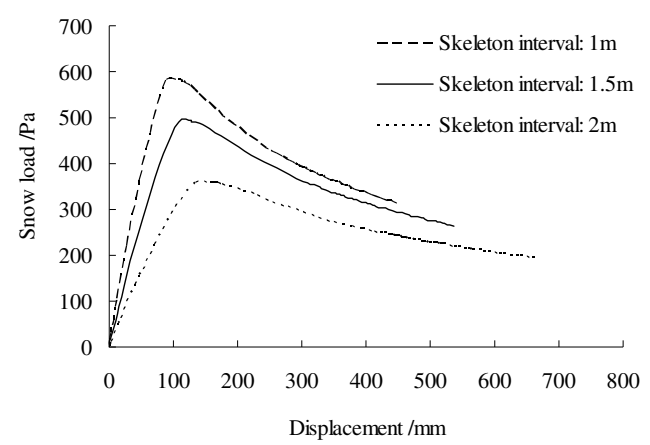

Fig. 8. Snow load-displacement curves of structures with different skeleton interval 


\subsection{Effect of Different PC Sun Board Thickness}

As shown in Fig.9, the greater the PC sun board's thickness is, the greater the lateral support is, the greater ultimate load is, and the smaller the maximum displacement is. And the shape of curves is similar. The ultimate load of structures with $6 \mathrm{~mm}, 8 \mathrm{~mm}$, $10 \mathrm{~mm}$ and $12 \mathrm{~mm}$ thick PC sun board, is respectively $448 \mathrm{~Pa}, 582 \mathrm{~Pa}, 672 \mathrm{~Pa}$ and $745 \mathrm{~Pa}$, increased by $29.9 \%, 15.5 \%$ and $13.2 \%$ in order. Compared with the result of structures with different number of purlins, the ultimate load to resist snowstorms of the structure with $8 \mathrm{~mm}$ thick PC sun board is comparable to that of the structure with 4 purlins, and $10 \mathrm{~mm}$ thickness comparable to 6 purlins, $12 \mathrm{~mm}$ thickness comparable to 8 purlins.

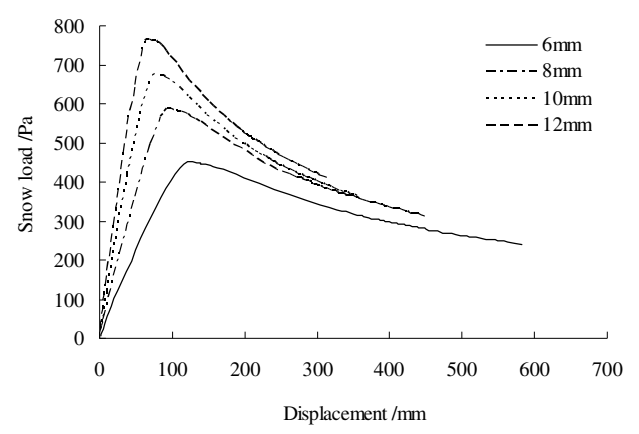

Fig. 9. Snow load-displacement curves of structures with different thickness of PC sun board

\subsection{Effect of Different Covering Materials}

As shown in Fig.10, the ultimate load of the structure with PC sun board is $582 \mathrm{~Pa}$; while the ultimate load of the structure with plate glass is $448 \mathrm{~Pa}$. The former is increased by $29.9 \%$ than the latter. The reason is that the in-plane shear stiffness of PC sun board is greater than that of plate glass. And in both cases the shape of curves is similar. It indicates that the collapse modes are both in-plane buckling.

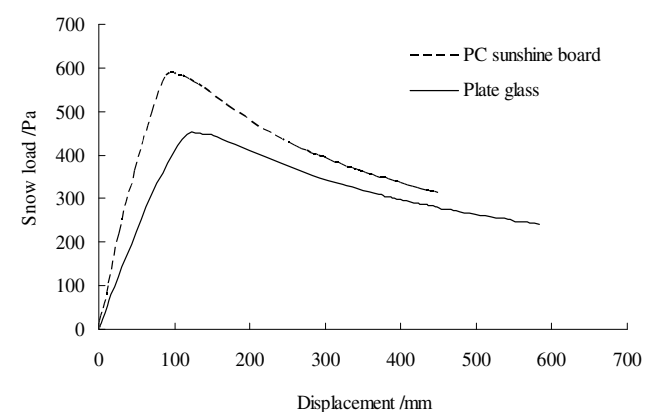

Fig. 10. Snow load-displacement curves of structures with different covering material 


\subsection{Effect of Different Constraint Condition}

The skeleton rotation capacity at both ends is directly determined by constraint condition at each end, and the ultimate bearing capacity of overall spatial structure is also affected by constraint condition. As shown in Fig.11, the ultimate load of both top and bottom clamped case is $716 \mathrm{~Pa}$, while both top and bottom hinged case is 582 $\mathrm{Pa}$. The ultimate loads of top hinged and bottom clamped, and top clamped and bottom hinged are respectively 627Pa and $645 \mathrm{~Pa}$

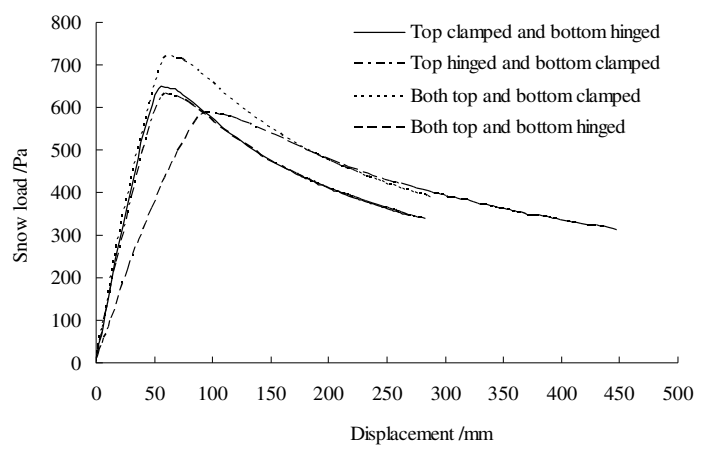

Fig. 11. Snow load-displacement curves of structures with different constraint condition

\section{Conclusions}

Under snow load, the collapse mode of overall spatial structure is in-plane buckling whenever the lateral support is provided by rigid plate covering or purlins. The skeleton interval determines the lateral support of rigid plate covering, thus affecting the ultimate bearing capacity to resist snowstorms. The increment of rigid plate covering's thickness improves the anti-snowstorm capacity as well. PC sun board is more effective comparing with other covering materials. Besides, increasing the skeleton steel tube section size can improve the ultimate capacity, but it will increase the amount of steel and construction cost simultaneously. Nevertheless, increasing constraint stiffness at both ends of the skeleton can increase the anti-snowstorm capacity, but causes less construction cost. Finally, rigid plate covering, such as PC sun board as translucent covering, can reduce the need of purlins. It is equivalent to purlins in some way.

However, the effect of stressed skin action in this paper is only investigated under snow load. For other loading cases, it needs further exploration. To simplify the calculation, the effect of gable at both ends of solar greenhouse is not taken into consideration. It is necessary to construct more realistic models for analysis to obtain more accurate results in future study.

Acknowledgments. Support for this research by Chinese Universities Scientific Fund No. 2011JS126, the Specialized Research Fund for the Doctoral Program of Higher Education of China No. 20110008120017, and the National Natural Science Funds No. 50979108. 


\section{References}

1. Wang, C., Shi, W., Pei, X.: Comparing the Front Roof Permeated Sunlight Performances and the Arch Mechanical Performances of Four Curvilinear Roofs of Solar Greenhouse. Journal of Northwest A \& F University (Natural Science Edition) 38, 143-150 (2010) (in Chinese)

2. Lu, X., Qiu, L.: Single-side Slope Sunlight Greenhouse Skeleton Finite Element Optimization. Transactions of The Chinese Society of Agricultural Machinery 36, 120-151 (2005) (in Chinese)

3. Li, C., Liang, Z., Ju, J.: Spatial Finite Element Analysis of Heteromorphous Greenhouse. Journal of China Agricultural University 12, 84-87 (2007) (in Chinese)

4. Fang, R., Lu, H.: Research on Design of Glass Greenhouse. Agricultural Engineering Technology (Greenhouse \& Horticulture) 9, 32-33 (2005) (in Chinese)

5. Engel, R.D.: Using Simulation to Optimize Solar Greenhouse Design. In: 17th Annual Symposium on Simulation, NJ, USA, pp. 119-139 (1984)

6. Tiwari, G.N., Dhiman, N.K.: Design and Optimization of a Winter Greenhouse for the Len-Type Climate. Energy Conversion and Management 26, 71-78 (1986)

7. Tiwari, G.N., Dubey, A.K., Goyal, R.K.: Analytical Study of an Active Winter Greenhouse. Energy 22, 389-392 (1997)

8. Liu, J.: Structure Optimization Design for Sunlight Greenhouse Skeleton Truss-work. China Agricultural University, Beijing (2008) (in Chinese)

9. Bai, Y., Ming, Y.: Analysis of Influence Factor on Safety and Durability of Steel Skeleton of Solar Greenhouse. Housing Materials \& Applications 5, 14-15 (2005) (in Chinese)

10. Yuan, X.: Skin-effect Theory and Research Profiles. Sichuan Building Materials 1(36), 73-74 (2010) (in Chinese)

11. JB/T 10286-2001, Greenhouse Load Design Specifications (in Chinese)

12. Wang, B., Jin, B., Song, J.: Finite Element Analysis of Load Bearing Capacity of Steel Skeletons for Solar Greenhouses Under Vertical Loads. Journal of Ningxia University (Natural Science Edition) 30, 337-338 (2009) (in Chinese)

13. Wang, X.: ANSYS Numerical Analysis of Engineering Structures. China Communications Press, Beijing (2007) (in Chinese)

14. Zhang, X.: Sunshine Board in Agricultural Greenhouse. Agricultural Engineering Technology: Greenhouse Gardening 5, 24-24 (2007) (in Chinese)

15. Huang, S., Pen, D.: Project Design of Greenhouse Sealed Aluminum Cover. Agricultural Engineering Technology(Greenhouse \& Horticulture) 12, 10-13 (2006) (in Chinese)

16. Chen, J.: Stability of Steel Structure Theory and Design. Science Press, Beijing (2001) (in Chinese)

17. Yu, Y., Wang, J., Ying, Y.: Nonlinear Finite Element Analysis of the Bearing Capacity of the Film in Plastic Greenhouse. Transactions of the Chinese Society of Agricultural Engineering 23, 181-185 (2007) (in Chinese)

18. Yu, Y., Wang, J., Ying, Y.: Nonlinear Finite Element Analysis of the Bearing Capacity of Arch Structure in Plastic Greenhouse on Snow Load Working Condition. Transactions of the Chinese Society of Agricultural Engineering 23, 158-162 (2007) (in Chinese) 